\title{
AGROINDÚSTRIA NO NORDESTE
}

(DA MODERNIZAÇÃO A MULTINACIONALIZAÇÃO) ${ }^{\prime}$

$M^{a}$ Lucia (ionçalves de Canalho²

\section{AATTRODUÇÃO}

Os incentivos colocados à disposição das empresas pclo Estaclo atra: iés da política de industrialização da SUDENE não foram na sua maior parte direcionados à indústria que transforma a matériaprima agricola, mas à indústria petroquímica. No entanto. a agroindústria que processa as frutas tropicais $\mathrm{co}$ tomate, que cxistiam no nordestc mcsmo antes da SUDENE, constitui uma exceção à regra, sendo os casos da Maguary S/A, localizada em Bonito-Pc. c da CICANORTE. $\mathrm{cm}$ juazeiro-Ba, uma ilustração dessa política. Em ambos os exemplos, a modunização da agricultura, através da maior utilização de máquinas. di; insumos químicos e da irrigação. permitiu que as matériasprimas agrícolas em quantidade c qualidades adequadas. atendessem às cxigencias úu setor indust iai. Este fato, observamos tanio na cultura do abacaxi em Sapé, na Paraiba. como na do tomate, nos perímetros

'Artigo extraido da tesc de doutorado "Les stratégies d'Agroindustrialisation et leurs Rapports avec l'Agriculture dans 10 Nordeste du Brésil - Les Industries de Transformation des Fruits Tropicaux et de la Tomate. Paris, EHESS, dez. 1991.

${ }^{2}$ Professora do Departamento de Economia - CH - UFPB Campina Grande. PB. Doutora em Sócio-Economia do Desenvolvimento. 
irrigados do Vale do São Francisco. Nestes, a irrigação implantada pclo setor público, através do DNOCS e da CODEVASF, atraiu muitas agroindústrias, principalmente a do tomate, constituindo, inclusive, um pólo agroindustrial, o qual utilizou-se também das vantagens do FINOR. administrado pela SUDENE.

Portanto, neste artigo. nosso objetivo é mostrar à partir da trajetória da MAGUARY S/A e da CICANORTE, nos anos 70 e 80 , como as politicas agricolas $\mathrm{e}$ industriais, embora atuando separadamente. mas seguindo a mesma lógica, criaram as condições para a implantação do modelo de desenvolvimento agroindustrial, atualmente predominante na região.

\section{A MAGUARY S/A: DO GRUPO FAMILIAR À EMPRESA MULTINACIONAL}

A MAGUARY S/A pertenceu durante três décadas à familia Tavares de Melo, que iniciou suas atividades econômicas no interior de Pernambuco. em 1920. À partir de um engenho que se transforma postcriormente. na Usina Olho d'Água. esse grupo familiar chega a constituir um dos mais destacados grupos agroindustriais do Nordeste.

Além do açúcar, o grupo Tavares de Melo, investe na produção do álcool. Em 1960, compra a Usina Estivas no Rio Grande do Nortc. com grande plantio de cana e uma destilaria anexa para produzir álcool carburante. Em 1974, é instalada a primeira destilaria autônoma. cm Pedras de Fogo, na Paraiba, denominada GIASA- Gramame Industrial Agrícola S/A.

Nos anos 50, o grupo Tavares de Melo estende sua atuação para o setor de transformação de frutas tropicais. Implanta as Industrias Alimenticias Maguary Ltda. ${ }^{3}$. em Pedras de Fogo-PB, em função da

${ }^{3}$ A Indústria muda várias vezes seu estatuto jurídico: 1952 Agroindustrial Livramento Ltda.; 1953 -Indústria Alimentícia Maguary Ltda. Em 1964, ela torna-se uma sociedade anônima. Nesse trabalho scrá denominada simplesmente MAGUARY S/A 
existência da produção de abacaxi. Mas, com o declínio dessa produção - totalmente substituída pela cana de açúcar - a fábrica foi transferida, nos anos 1960, para o município de Bonito, em Pernambuco ${ }^{4}$.

Logo após a sua implantação em Bonito, a MAGUARY S/A, enfrenta problemas com relação ao fornecimento do caju, que era cultivado ao lado do café. A política implantada, em junho de 1963, pelo próprio Instituto Brasileiro do Café - IBC (criado nos anos 30 e desativado em março de 1990) previa erradicar os cafezais de menor rentabilidade, pois havia uma superprodução no pais.

Como o café é uma cultura que absorve muita mão-de-obra, a agricultura do Nordeste, saiu prejudicada, em sua função social de gerar emprego. O café produzido nos estados de Sergipe e da Bahia foi totalmente erradicado, pois apresentava rentabilidade muito inferior à conseguida, por exemplo, nos estados do Paraná e São Paulo. Mesmo com a diminuição da oferta local de caju, a MAGUARY S/A manteve sua unidade em Bonito. Ela adquiria a matéria-prima em outras localidades e para compensar, foi introduzida uma nova linha de produção, a dos derivados do coco. Contudo, a empresa continua sua marcha expansionista, estimulada pelo sistema de incentivos fiscais e financeiros estabelecidos pela SUDENE. Foi beneficiada também com o DecretoLei $n^{\circ} 1199$ de 1971 que reduz à zero o IPI, para a indústria de suco.

Nos anos 1970, a MAGUARY S/A instala novas fábricas em vários estados: Araguari-MG, em 1974; Aracati-Ce, em 1978 e amplia a de Bonito-Pe, em 1978. Ela inicia também em 1970 a produção de sorvetes de frutas tropicais em Recife-Pe. O projeto da fábrica é financiado pela SUDENE. De imediato, a MAGUARY S/A lidera todo o

${ }^{4} \mathrm{~A}$ transferência pode ser explicada tanto por razões econômicas como políticas. Em $1^{\circ}$ lugar, havia em Bonito-Pe uma grande produção de caju, ao lado da plantação de café; $2^{\circ}$, o Estado de Pernambuco estava oferecendo vantagens fiscais à industrialização; $3^{\circ}$, a recusa por parte do Governo da Paraíba ao pedido da Maguary, para asfaltar o trecho Goiana-Pedras de Fogo, a fim de facilitar o escoamento da produção. 
mercado do Nordeste, que era suprido, até então, pelos produtos da Kibon S/A Industria Alimentícia, vindos de sua fábrica em São Paulo.

A KIBON S/A à exemplo da MAGUARY S/A, pleiteou junto à SUDENE, um financiamento para a instalação de uma unidade industrial. Com o projeto aprovado em 1970, foi implantado em Jaboatão, cidade vizinha à Recife, a KIBON do Nordeste S/A Produtos Alimentícios. Esta pertence ao grupo da General Foods, empresa norteamericana, com outros investimentos na América Latina e especializada na fabricação de alimentos.

O mercado de sorvetes e picolés do Nordeste, por um período de 06 anos, foi suprido pelas duas empresas. A fábrica de sorvetes da MAGUARY S/A embora dispondo de sólida experiência na fabricação de sorvetes de frutas, começa a apresentar prejuizos. 0 problema era de natureza mercadológica, uma vez que ela devia enfrentar a concorrência dos sorvetes cremosos, produzidos pela KIBON do Nordeste. Além disso, a oferta de sorvetes era muito superior à demanda regional - ficava cm torno de 8 a 9 milhões de litros - e a capacidade de cada fábrica cra para produzir 11 milhões de litros, por ano. Uma saída viável seria diminuir a produção, através da eliminação de parte da capacidade instalada. Isso de fato ocorreu, através da formação de uma "joint venture" entre a KIBON do Nordeste e a MAGUARY S/A. A nova empresa - Sorvetes Alimenticia do Nordeste S/A - SORVANE, conhecida pela marca MAGUARY/KIBON, continua a funcionar em JABOATAO-Pe. A criação desta em 1976 - primeira fusão de uma empresa do grupo com outra de capital estrangeiro - registra o primeiro sinal de debilidade e abre um espaço à multinacionalização.

Por outro lado, os Tavares de Melo, que possuíam desde 1958 a Fazenda Buracão em Sapé na Paraiba ${ }^{5}$,continuam a investir no setor agrícola e constituir em 1980 na praia de Lucena-Pb a empresa

${ }^{5} \mathrm{Na}$ Fazenda Buracão era plantado o abacaxi destinado a ser processado inicialmente em sua fábrica de Pedras de Fogo e, depois, em Bonito. 
Maguary Agrícola Ltda. ${ }^{6}$, para garantir o fornecimento adequado de matéria-prima para suas fábricas. Nessas fazendas é feito o plantio dc coco, cujo projeto financiado pela SUDENE, apresenta alto nivel tecnológico. As sementes hibridas - do tipo PB 121 e PB 111 - são importadas da Costa do Marfim, na África, cujo rendimento é muita vczes superior ac do coqueiro nativo. Além do projeto para a implantação do coco, a SUDENE financia para a mesma Fazenda, um outro projeto, cuja finalidade é aumentar a área irrigada e evitar o recuo do plantio. pois o coco é muito exigente em água, consumindo cada pé, 25 litros por $\mathrm{dia}^{7}$.

Em Araguari-MG, o Grupo comprou em 1981 a Fazenda Sta. Helena, que fornecia parte do maracujá transformado na fábrica local. Essa Fazenda tendo sido vendida em 1988, a fábrica, como fazia anteriormente, continua a comprar a matéria-prima dirctamente do produtor, alem de fomecer insumos e prestar assistência técnica, como parte integrante de sua estratégia de integração. $O$ banco exige para liberar empréstimos para estes produtores, uma carta de anuência da MAGUARY S/A, o que caracteriza uma situação de dependência destes à agroindústria.

As diferentes estratégias praticadas com sucesso pelo Grupo Tavares de Melo, com a participação de três gerações da família. permitiram a MAGUARY S/A, registrar tanto no setor agrícola como no industrial, um amplo processo de expansão e uma intensa diversificação das atividades, conforme acabamos de ver.

${ }^{6}$ Em Lucena - a Maguary Agrícola Ltda. - com uma superficie total de 2.437 ha, é formada por 3 fazendas: a Faz. Mangereba com 845 ha $(34,7 \%)$; a Faz. Vale do Mangereba com 824 ha $(33,8 \%)$ e a Faz. Saué com 768 ha $(31,5 \%)$. Elas foram adquiridas $\mathrm{cm} 1979$.

${ }^{7}$ A Maguary Agricola Ltda., mesmo sendo localizada na zona litorânca, registrou, nos últimos anos, uma diminuição na precipitação pluviométrica de $878 \mathrm{~mm}$, caiu de $2.627 \mathrm{~mm}$ para $1.749 \mathrm{~mm}$, entre 1987 e 1988. 
No entanto, sua eliminação como grupo nacional e regional, ocorreu $\mathrm{cm}$ julho de 1984. A indústria MAGUARY S/A constituida de três fábricas e duas fazendas foi comprada pela Companhia SOUZA CRUZ. filial brasileira da British American Tobacco. 0 Grupo Souza Cruz - uma holding formada por 16 empresas - desenvolve atividades em vários setores, onde destacam-se os de Fumo e Cigarros, Papel e Celulose, Sucos e Associados. Afora a indústria, o Grupo atua na pesquisa, na agricultura, no comércio, na administração de imóveis e seguros.

A SOUZA CRUZ é um dos mais importantes grupos econômicos do complexo agroindustrial brasileiro, principalmente no setor de Fumo e Cigarros. Com 06 fábricas e uma enorme rede de distribuição em todo o Brasil, ela controla $78,8 \%$ do mercado nacional ${ }^{8}$, sendo citada como o maior contribuinte privado do pais. Este grupo passou a controlar a MAGUARY S/A, em 1984, adquirindo 100,0\% das ações ordinárias c $54,0 \%$ das preferenciais. Em termos de capital total da empresa. essas ações representam $81,4 \%$. Em outubro do mesmo ano, outras ações foram compradas, o que elevou sua participação a $8.10 \%$.

As atividades da SOUZA CRUZ se estendem a todas as regiõcs do Brasil. e scus produtos se encontram em todos os continentes. Es a participação nos vários mercados deve-se a qualidade, de seus produtns. que segundo a avaliação dos seus diretores é o resultado de seus investimentos na pesquisa e no desenvolvimento tecnológico. É no set $r$ de Fumo e Cigarros que o grupo SOUZA CRUZ mais se destaca na cconomia brasileira. Porém o que nos interessa ressaltar é sua atuacão cnquanto proprietário da marca MAGUARY S/A, marca que continua a 'iderar o mercado interno de sucos tropicais, participando com $45.0 \% 11$

${ }^{8}$ Isto É. março de 1990, Rio de Janeiro. Editora Três. 3OUZ: CRUZ (1985), iuformativo Scuza irus. "SOUZA CRUZ (1985), w"̄. sit 
A MAGUARY S/A integra-se administrativamente a SUVALAN, localizada em Bento Gonçalves no RGS, para formar a Indústria de Sucos e Produtos Associados da SOUZA CRUZ. Sua experiência na fabricação de suco é recente, pois começou em 1976, produzindo suco concentrado de uva e em menor quantidade de laranja. Em seguida acrescenta outras frutas como a maçã e o limão. Seus produtos secundários são o estrato da uva e o acido tártaro, largamente utilizado na indústria farmacêutica.

A MAGUARY S/A, agora sob controle da SOUZA CRUZ, encaminhou projeto à SUDENE, em 1988, com a finalidade de ampliar e modernizar a fábrica de Bonito-Pe e Aracati-Ce. Segundo a classificação $^{11}$, com base nos critérios previamente estabelecidos - de localização, origem da matéria-prima, uso intensivo de mão de obra - o projeto obteve o percentual máximo $(40,0 \%)$ do FINOR, para projetos vinculados, direta ou indiretamente, ao capital estrangeiro.

Convém destacar que o grupo SOUZA CRUZ mencionado entre os maiores no Brasil, iniciou suas atividades à partir de uma pequena unidade artesanal e tornou-se um grupo multinacional ${ }^{12}$, o que evidencia traços comuns com a MAGUARY S/A na sua trajetória rumo à multinacionalização.

${ }^{11}$ Essa classificação seleciona os projetos por faixa de prioridade. Em função do resultado, varia a participação do FINOR nas inversões totais.

${ }^{12} \mathrm{O}$ grupo SOUZA CRUZ iniciou sua história em 1903, quando o imigrante português Albino Souza Cruz instalou uma fábrica de cigarros no Rio de Janeiro. O fumo era enrolado em papel, o que o diferenciava dos outros. $\mathrm{O}$ resultado foi uma expansão do mercado e como conseqüência uma ampliação dos negócios. Em 1914, a empresa se transformou em uma sociedade anônima e o controle de suas ações foi adquirido por uma companhia inglesa - a British American Tobacco - que adotou técnicas mais modernas no processo de fabricação. 
Em resumo, constata-se que a evolução da empresa MAGUARY S/A, desde o grupo familiar Tavares de Melo ao multinacional SOUZA CRUZ, tem como instrumento de expansão os mais diversos incentivos, desde o apoio da SUDENE à isenção de impostos. Enfim, são mais de trinta anos de financiamento, em condições excepcionais, tanto no setor industrial como no setor agrícola.

\section{A CICANORTE: DA EMPRESA NACIONAL A MULTINACIONAL}

$O$ pólo agroindustrial, constituído das cidades JuazeiroPetrolina, separadas apenas pela ponte Presidente Dutra, construída no início dos anos 50, se destaca no Vale do São Francisco. Elas possuem além de um número significativo de unidades industriais, um sistema bancário expressivo e um setor comercial que funciona como fator de atração na região. Ao lado disto, não podemos deixar de remarcar que o escoamento da produção utiliza, ao lado do transporte rodoviário e ferroviário, a frota da FRANAVE, empresa pública criada em 1963, cuja extinção foi anunciada em fevereiro de 1989 como parte da política de privatização do Plano Verão. No entanto, sua continuação, enquanto empresa pública, é devida a influência política, tanto à nível estadual como federal, da familia Coelho de Petrolina.

Ao lado das vantagens "locacionais", o Estado, através de seus diversos mecanismos, investiu muitos recursos no Vale do São Francisco, os quais atuaram principalmente em duas frentes: a modernização da agricultura, através dos projetos de irrigação, apoiados pelo sistema de crédito rural e da assistência técnica; e no estímulo à agroindústria local, através dos incentivos fiscais e financeiros da SUDENE, juntamente com o BNB. Paralelamente, a inclusão de Petrolina/Juazeiro no programa de Cidade de Porte Médio elaborado pelo Governo Federal, contribuiu para que estas cidades aumentassem sua importância no semi-árido.

Todas estas ações refletem-se no crescimento demográfico do Submédio São Francisco. Conforme dados do IBGE, entre os anos 1970 e 1980, a população do Submédio passou de 377,6 mil habitantes para 552,9 mil, sendo a taxa anual de $3,8 \%$. Comparada com o Brasil, 
cuja taxa foi de $2,6 \%$ no mesmo periodo, conclui-se que o crescimento foi significativo. Todavia, os municipios de Juazeiro e Petrolina, dentre os dezoito do Submédio, merecem um certo destaque, pois suas taxas anuais foram de $7,9 \%$ e $6,1 \%$ respectivamente.

Os dados para Petrolina evidenciam a grande modificação na estrutura ocupacional. As atividades agropecuárias que em 1960 ocupavam $59,9 \%$ da população economicamente ativa, diminuem para $34.2 \%$ em 1980. Ao passo que, no mesmo período, as atividades secundárias passam de $7,3 \%$ para $20,7 \%$, o que bem demonstra a importância que assume a indústria. Esta, à medida que se instala. desenvolve também as atividades de comércio e de serviços, as quais polarizam para Juazeiro e Petrolina a mão-de-obra das cidades vizinhas. A participação do terciário, na absorção de mão-de-obra, passou de $33,2 \%$ para 41,6\%. entre 1960 c 1980, em Petrolina.

Se. for feita a mesma análise para Juazeiro. observa-se que a participação da população nos setores de atividades. guarda uma semeIhança com relação à Petrolina. Em 1960, o setor secundário ocupava $8.9 \%$ da população economicamente ativa. e em 1980. o mesmo chega à atingir $30.9 \%$. Em virtude do aumento da participação do setor secundário. essas cidades são consideradas como pólo agro-industrial.

A transformação dos produtos primários se instala e se dinamiza sobretudo nos últimos anos. No distrito industrial de Petrolina inaugurado em 1980. pelo então Governador Nilo Coelho -. predomina a agroindústria processadora de tomate. Ela ocupa cinto e vinte oito hectares. ou seja $25.0 \%$. dos quinhentos hectares. Ccrno o processamento do tomate consome uma grande quantidade d'água. as indústrias sc localizam. de proferência. às margens do Rio.

Nas décadas de 70 e 80 . várias indústrias entram em operação. o que coincide com a cxpansão das áreas irrigadas. tanto privada como pública. através da instalação dos perimetros. Entre as făbricas instaladas no pólo destaca-se a CICANORTE $(1974)^{1,3}$. a ETT1...

${ }^{13} \mathrm{~A}$ capacidade total de transformação de tomate da CIC $A$

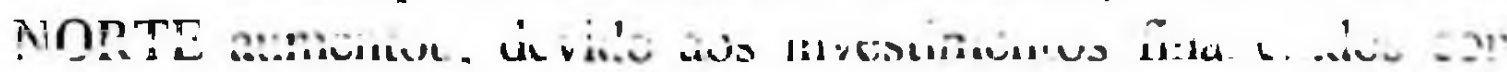


1982, e a FRUTOS DO VALE - do grupo Coelho - em 1986. Todas essas ações se refletem no crescimento demográfico do Submédio São Francisco. No ano de 1988, novos projetos para o tomate foram aprovados, sendo dois em Petrolina - a ampliação da ETTI e a instalação da fábrica CONSERVAS COLOMBO - e o outro, em Pesqueira - a ampliação da PELXE.

Mesmo com os novos projetos é necessário uma maior capacidade instalada para absorver a grande produção de tomate da região. Entre 1960 e 1980 , a agricultura irrigada - aumentou de 9.913 ha em 1970 para 43.315 ha em 1980 - estimulou esse plantio. Só a área irrigada pela CODEVASF (36.500 ha), produz 2.100.000 ton. de tomate por safra. ${ }^{14} \mathrm{~A}$ irrigação privada que abrange, quase a mesma superficie, deve ser também considerada.

Esse pólo agroindustrial, com capacidade para produzir 500 mil toneladas anuais de polpa de tomate, fornece um terço da quantidade consumida no país, em torno de 700 mil toneladas, por ano ${ }^{15}$.

No processo de agroindustrialização do Vale do São Francisco, investimentos à montante e à jusante da agricultura são atraídos para o dipolo. No primeiro caso, têm-se as indústrias de insumos agricolas como a Agromeca, a Valefértil, e no segundo, as de equipamentos e de bens intermediários, como a Dantas Irrigação, a Sometal, a Metal

cursos do FINOR. Em 1978 era de 3 mil toneladas; em 1983 de 50 mil toneladas; em 1985 de 145 mil e no final dos anos 1980, era de 300 mil toneladas por ano. Segundo MAFFEI, "para esmagar 150 mil toneladas de tomate, estima-se que sejam necessários 4 mil hectares irrigados de tomate, com uma produtividade média de 38 toneladas por hectare" (Affei, E. et alli, 1986, op. cit, p.41).

${ }^{14}$ No período da entressafra (de outubro à janeiro), o plantio de tomate é reduzido, devido as altas temperaturas; o que favorece o ataque das pragas. Nos meses de janeiro, planta-se cebola, banana e milho. 
Gráfica, etc. Ao lado dessas, outros tipos de indústrias se desenvolvem no parque industrial de Petrolina, como a de confeç̧ões (New River Ind.e Com.), e as de plantas aromáticas e medicinais (uma do grupo Matarazzo e outra do grupo Sanrisili). No contexto da expansão desse pólo agroindustrial, interessa ressaltar a experiência da CICANORTE, na sua trajetória rumo à multinacionalização.

Em 1974, o Grupo CICANORTE estabeleceu-se em Pesqueira-PE, com a finalidade de processar o tomate. Lá chegando comprou as instalações da CIAPE $^{16}$, que pertencia ao atual proprietário da ROSA, outra empresa do mesmo ramo. Mas, devido a falta de matériaprima no local, foi obrigada a encerrar suas atividades e transferir-se para Juazeiro, pois $60,0 \%$ do tomate provinha dos perímetros irrigados.

Por essa razão a CICANORTE iniciou suas atividades na Bahia, em 1977. Como não havia nesse Estado indústria similar, a SUDENE financiou, através do FINOR, as inversões fixas necessárias. Ela obteve também uma redução do Imposto de Circulação de Mercadorias (ICM), bem como do Imposto de Renda.

Uma outra vantagem seria sua localização às margens do São Francisco, pois assim ela retira a água do rio sem nenhum custo financeiro e a transformação do tomate, com base na pasteurização, consome grande quantidade de água. Mesmo que a CICANORTE opere, apenas, no período de junho a novembro, devido principalmente ao calendário agrícola do tomate, sua capacidade de produção se expandiu nos anos 1980. Como parte dos incentivos da SUDENE, a capacidade de produção dos dois concentradores aumentou em 1989, passando de 900 ton./dia para 1.350 ton./dia.

Estes resultados colocam o grupo CICA (Cia industrial de Conservas Alimentícias) em primeiro lugar entre as indústrias processadoras de tomate da América Latina. Em segundo lugar, vem a

${ }^{16}$ A CIAPE (Cia e Ind. de Alimentos de Pernambuco), cujas instalações encontravam-se em condições precárias, pertencia ao Sr. Severino Paixão, atual proprietário da unidade industrial "Rosa". 
ARISCO, localizada em Goiânia-Go, que processa a polpa adquirida de várias empresas e, em terceiro lugar, a ETTI, com unidades em São Paulo e em Petrolina. Em seguida, a Peixe, também localizada em Petrolina.

O leque de possibilidades é extremamente vasto. Entre os produtos finais destacam-se o extrato e os diferentes tipos de molho. A polpa, produto intermediário, produzida em Juazeiro é enviada em tambores de $200 \mathrm{~kg}$ - com brix bastante elevado, para evitar o transporte d'água - para a unidade da CICA em Jundiaí-SP, sua coligada.

O equipamento para produzir polpa é semelhante ao utilizado para fabricar o produto acabado. $O$ que falta em Juazeiro é apenas montar a linha de produção. A CICA de Jundiaí exporta a polpa para os países da América do Norte, América do Sul e Europa, e vende o produto final para o mercado nacional, inclusive o Nordeste.

Essa empresa, inicialmente familiar, também encontrou na região todas as facilidades para investir na agricultura. Além do mais, ela já contava com a experiência na área agrícola, pois já atuava no setor, em São Paulo.

O grupo CICA, de propriedade dos imigrantes italianos, MESSINA E BONFIGLIOLI, iniciou suas atividades nos anos 1940, em Jundiai -SP, onde plantavam uva e produziam vinho, de uma forma artesanal. Em seguida passou a fabricar o extrato, à partir do tomate. Este grupo constitui-se à partir de várias empresas, com estatutos jurídicos diferentes e localizadas em espaços geográficos também diversos.

Ela possuía várias unidades industriais: três no estado de São Paulo, nas cidades de Presidente Prudente, Monte Alto e Jundial; uma, na região Nordeste, a CICANORTE, em Juazeiro, e outra no Rio Grande do Sul, a CICASUL, que transforma frutas como figo, pêssego e maçã. Na unidade de Jundiaí é elaborado o produto final à partir da compra da polpa fabricada na CICANORTE e nas demais fábricas de São Paulo.

No ano de 1983, o grupo estende seus negócios até a Argentina, onde compra e amplia uma fábrica para industrializar a ervilha. 
Antes, o grão era importado e enlatado em Jundiai-SP. Apesar de toda a dispersão geográfica, as estratégias de expansão eram definidas para o grupo como todo. $O$ processo produtivo na esfera industrial assim como o sistema agrícola eram definidos em suas linhas gerais. Como parte destas, várias ações são estabelecidas, no que diz respeito: - à qualidade da matéria-prima a ser produzida; - à forma de seu fornecimento; - ao desenvolvimento de novas tecnologias; - e, à sua divulgação entre os produtores rurais.

Os descendentes dos imigrantes italianos - MESSINA e BONFIGLIOLI - formaram um importante grupo econômico, em termos da economia nacional. A atuação de suas 53 empresas atingiam diversos setores, como o bancário, o mobiliário, o agroindustrial e a agricultura propriamente dita. Mas, desde novembro de 1985 a Corporação BONFIGLIOLI defronta-se com os sintomas de uma crise, que selaria seu desaparecimento. Ela tenta superar as dificuldades surgidas em sua ramificação na área financeira: a falência do Banco Auxiliar décimo segundo maior banco privado do país.

Mas, a dívida de um dos maiores acionistas do grupo. Rodolfo Bonfiglioli, junto aos credores privados do país e do exterior, era muito elevada. Mesmo após sucessivas injeções de recursos, através do socorro interbancário do Banco Central do Brasil, não houve outra saída, senão a venda. Entre os grupos interessados o grupo FERRUZZI foi escolhido.

FERRUZZI - segundo grupo privado italiano - através da MOVEPI, sua holding no Brasil, adquiriu 98,0\% das ações ordinárias da CICA, o que the permite controlar 57,0\% do capital total da empresa. Mas, não é com a aquisição da CICA em 1987, que o citado grupo inicia seus investimentos no Brasil. Ele já se fazia presente, desde $1974^{17}$.

${ }^{17}$ Entre seus muitos empreendimentos, a Ferruzzi, atualmente, planta maçãs em Friburgo-SC; tem um projeto agro-industrial em Alta Floresta-MG, onde explora 1 milhão de pés de café, 350.000 pés 
Dessa forma, a CICA, que pertencia à corporação BONFIGLIOLI, após quase meio século de remarcável expansão, é vendida ao grupo FERRUZZI, em abril de 1987. Assim, o grupo CICA, a maior e mais tradicional fabricante de conservas do país, teve seu fim, enquanto grupo naciona $1^{18}$. Após traçar, de forma resumida, a expansão e declínio do grupo Bonfiglioli, constata-se que de muito assemelha-se ao do grupo Tavares de Melo.

\section{A AGROINDÚSTRIA E SUA REPERCUSSÄO NO DESEN- VOLVIMENTO REGIONAL}

Nos anos 80, a agroindústria no Nordeste, implantada com o apoio do Estado apresenta em determinados setores uma extraordinária expansão. A indústria de suco de frutas tropicais e a dos derivados do tomate ocupam uma posição privilegiada com relação à economia nacional e contribuem para a diversificação da estrutura agro-industrial da região, conforme foi analisado neste artigo, através das empresas de maior performance entre suas similares, como a MAGUARY S/A e a CICANORTE.

A MAGUARY S/A, uma das mais destacadas empresas de suco de frutas do Nordeste, lidera a preferência para os sucos de manga, maracujá e goiaba, no mercado brasileiro. Com relação aos derivados do abacaxi, em 1987, sua participação para o suco integral foi $40,5 \%$ da produção nacional e de $54 \%$ para o abacaxi em conserva. A CICANORTE, filial do grupo nacional CICA, a partir do fornecimento do tomate proveniente dos perímetros irrigados do submédio São Francisco, ocupa o primeiro lugar na produção dos derivados do tomate no Brasil e, inclusive na América Latina.

de cacau e 400.000 mil cabeças de gado, numa extensão de 350.000 hectares. VEJA, fevereiro, 1987, Editora Abril, São Paulo.

${ }^{18}$ Veja, op. cit. 
A evolução dessas empresas enquadra-se na própria história da agroindústria do Nordeste e, portanto, elas apresentam vários pontos em comum, nas suas trajetórias de expansão, como por exemplo:

- iniciaram suas atividades econômicas como pequenas empresas familiares, do tipo artesanal;

- foram beneficiadas com a política de industrialização do Nordeste através dos incentivos fiscais e financeiros; e, pela política agrícola de modernização da agricultura, principalmente através da implantação dos perímetros irrigados no submédio São Francisco;

- investiram na produção agrícola e se integraram aos demais produtores através dos contratos de comercialização, da transferência de tecnologia, do fornecimento de insumos;

- ocuparam uma posição de destaque entre os mais importantes grupos agroindustriais regionais e nacionais; e, posteriormente, foram adquiridas por empresas multinacionais.

Mas, resta a saber, em que sentido, esse modelo implantado na região com o apoio do Estado, contribuí para o desenvolvimento regional, em termos de uma maior oferta de emprego e de valor agregado, no contexto de uma produção adequada à estrutura da demanda regional?

Os produtos da MAGUARY S/A são consumidos, em sua maior parte, no mercado do centro-sul por uma camada da população que possuí um elevado nível de renda. 0 mercado do Nordeste, no final dos anos 80 , absorveu apenas $6 \%$ de sua produção, o que pode ser justificado pelo baixo poder de compra da população, cuja maioria está incluída numa faixa de renda que não atinge, sequer, um salário mínimo regional. Além dos seus produtos serem inadequados à demanda regional, a MAGUARY S/A não adquire no mercado do Nordeste, e sim no do centro-sul, os produtos para o acondicionamento do seu produto final como as garrafas, as etiquetas e os tambores. A consequiência disto é que a expansão do setor de frutas tropicais não induziu novas atividades industriais à sua montante, o que representa em termos 
da economia regional a não criação de maior valor agregado e de novas oportunidades de emprego.

Com relação ao fornecimento da matéria-prima, a agroindústria MAGUARY S/A estabelece diferentes articulações com os seus fornecedores, sendo a assistência técnica um dos principais elos que reforçam a interdependência dos setores na cadeia agroindustrial. Além de que, a integração não deixa de ser um processo desigual, pois a agroindústria determina o que, como e quando produzir, em função de suas necessidades. Mesmo quando o fornecimento é do tipo indireto, o intermediário como legítimo representante da fábrica, introduz modificações no padrão técnico entre os produtores agrícolas, conforme os exemplos do abacaxi e do maracujá.

A modemização da produção de abacaxi de Sapé baseada na adoção dos insumos químicos resultou na elevação dos custos de produção. Como consequêencia essa atividade tornou-se bastante seletiva com relação aos pequenos e médios produtores. Além disso, as modificações ocorridas na política de crédito agrícola, no início dos anos $\mathbf{8 0}$ os obriga a vender antecipadamente sua produção aos intermediários.

Podemos remarcar, de passagem, que as técnicas difundidas junto aos produtores são, desde a absorção da MAGUARY S/A pela SOUZA CRUZ, concebidas à partir da pesquisa elaborada e dirigida pelo laboratório da empresa em São Paulo. Essa situação não deve ser a melhor, levando em conta os interesses dos agricultores nordestinos.

Considerações semelhantes podemos fazer sobre a indústria de transformação de tomate, cujo desenvolvimento também resulta dos subsídios à industrialização. No caso da CICANORTE, o ciclo industrial não se completa na região, pois a polpa do tomate produzido nesta empresa é transformada em produto final na CICA de São Paulo distante uns três mil quilômetros - e vendido no mercado do Nordeste. Mesmo sendo um produto popular - acessível ao poder de compra de uma grande faixa de consumidores - o custo de transporte torna seu preço mais elevado e, por cima, a economia do Nordeste perde a oportunidade de gerar mais valor agregado e novos empregos. 
Além da política de industrialização, a agroindústria do tomate foi fortemente apoiada no decorrer dos anos 70 com a implantação da irrigação no submédio São Francisco. Observamos nos perímetros estudados que a área destinada aos empresários é muita vezes superior a dos colonos, o que reforça a concentração da estrutura fundiária na região. Como exemplo podemos citar, o caso da AGROVALE S/A usina de açúcar e destilaria de álcool - que possuí aproximadamente $73 \%$ da área do Perímetro de Tourão e, em menor proporção a CICANORTE, que possui quase $40 \%$ da área irrigada do perímetro de Mandacarú.

Portanto, a modernização da agricultura, através da irrigação, criou as condições para o desenvolvimento agroindustrial. Petrolina e Juazeiro torna-se um pólo de atração regional com um forte aumento populacional e uma modificação substancial na estrutura ocupacional: a população ativa participa em maiores proporções da atividade do setor secundário, ao passo que nos estados da Bahia e Pernambuco como nas respectivas microrregiões, predomina as atividades primárias tradicionais. Em virtude do aumento da participação do setor secundário, as atividades de comércio e de serviços se desenvolvem e polarizam a mão de obra das cidades vizinhas. Essa realidade é um prolongamento do processo de urbanização ocorrido no Brasil nos anos 70 e também no Nordeste, nos anos 80 .

No pólo agroindustrial, os projetos de irrigação substituem a agricultura de subsistência pelos produtos comerciais como o tomate, a cebola, o melão, a melancia, a uva, o aspargo e a cenoura, entre outros. Esta transformação contribui para a diminuição da produção da mandioca, do milho e do feijão destinada à população menos favorecida, que segundo a Organização Mundial da Saúde apresenta padrões de nutrição abaixo do desejado. A verdade é que o aumento da produção de alimentos continua a exigir uma atenção especial dos formuladores das políticas públicas do setor agrícola, não somente a modernização da produção agrícola concentrada em determinadas áreas, atenderá as carências regionais.

O sistema agrícola implantado nos perímetros, da mesma forma que para o abacaxi, caracteriza-se pelo uso intensivo dos insu- 
mos químicos, os quais chegam a participar, em torno de $40 \%$ no custo de produção dos diversos produtos, o que serve para afastar muitos produtores da atividade. Contrariamente ao que ocorre com a produção do abacaxi, a demanda criada pela agricultura irrigada induz a instalação de novas atividades industriais com a finalidade de produzir os insumos químicos, os equipamentos e os bens intermediários utilizados na irrigação. Esses elementos são fundamentais na formação do complexo agro-industrial.

A análise do modelo agroindustrial implantado no Nordeste com apoio do Estado, embora apresente resultados econômicos bastante positivos, chegando, inclusive a atrair grupos multinacionais, não apresenta a mesma repercussões a nível do emprego e da produção de alimentos. Podemos dizer que o modelo agroindustrial não mudou substancialmente o quadro do subdesenvolvimento do Nordeste, o que nos permite concluir que o esforço da agroindustrialização e da modernização da agricultura significou, em termos do desenvolvimento regional, o uso irracional das potencialidades da região - dos seus solos agrícolas, do seu parque industrial e, uma agressão ao meio ambiente cm troca da criação de poucos empregos, que não contribuem para aumentar o nivel de renda da população mas, para perpetuar o ciclo da pobreza. 